\title{
Putting community first: supporting (a)synchronous interaction and belonging in online learning
}

\section{lan Garner}

Queen's University, Kingston, Canada

\section{Lindsay Heggie \\ Queen's University, Kingston, Canada}

Keywords: online learning; belonging; community; academic success; Covid-19.

\section{The challenge}

Student Academic Success Services (SASS) is a writing centre and learning strategies unit that supports the 24,000 students at Queen's University in Kingston, Canada. We do not directly support faculty's pedagogical development and instructional design. Instead, we provide students with academic skills and writing support through workshops, appointments, and drop-in sessions and groups. SASS's mission is as much about students' lives as their learning experiences. We believe that supporting students' sense of belonging and community are central to academic success (for example, Bliuc, et al., 2011; Strayhorn, 2012; Reynolds et al., 2017; Suhlmann et al., 2018), and help them persist in the face of challenges (Hoffman et al., 2002; Strayhorn, 2012). Developing a sense of belonging leads to feelings of community, and community boosts success.

The abrupt transition to online learning in March 2020 threatened to hit our communitybuilding mission hard. Gone were the shared spaces and sites of interaction. Gone were the opportunities for structured writing groups, workshops and drop-in programmes. Gone were the chance meetings, the reassuring nods of a classmate, and the safety in numbers of the typical learning community. Worse still, gone were the opportunities to identify students who struggled to engage in the community at a large institution. 
Our first remote efforts were hardly community-centric. We churned out reams of videos, handouts and semi-interactive modules to be completed asynchronously and alone. In our attempts to make resources available, and worried that live events would exclude students abroad, we focused on self-led and asynchronous content that had no opportunities for interaction or discussion. Students soon began to report that they felt alone and removed from the scholarly community and that their motivation was flagging.

\section{The response}

Without the time or money for large-scale solutions, we sought cheaper, simpler ways to foster community and belonging through a sense of shared time, place and support. Our approach, which draws on research from higher education and innovations from learning development and writing centres and student affairs departments at Queen's and beyond, may help meet the central human needs of belonging and community (Strayhorn, 2012). It might even improve on some more costly solutions in the university context.

From mid-autumn 2020 on, we have strived to include multiple, smaller opportunities for interaction and therefore community-building in every part of our work. For example:

- Video lectures were sent to course instructors with suggestions for discussion questions; a live, recorded Q\&A with the chance to pre-submit questions often followed.

- Interactive online tutorials - built using the inexpensive Rise Articulate e-learning platform (an online course creation tool which cost us approximately $\$ 450$ USD per year) - were revised to embed free third-party elements such as Padlets and Google Jamboards where students could publicly share their ideas, opinions and responses to learning.

- We asked student volunteers to run 'Study With Me' Instagram Live events (live footage of a person studying; Lee et al., 2021) and online Zoom study halls (in which student leaders talked through their study processes as attendees worked on their own material, answered questions and chatted with each other). These events introduced 'informal social learning spaces' (out-of-class spaces where learning 
takes place and where increased belonging and completion of academic work mutually reinforce one another (Matthews et al., 2011).

- We added a second informal social learning space - an entirely new online weekly study hall component, emulating Instagram Live events via Zoom - to our mentor programme for students who performed poorly in first semester.

- We turned our graduate drop-in programme into an online community to reduce student isolation. We held twice-weekly live check-ins, created a repository of resources, and facilitated discussion via Microsoft Teams. Students participated in scheduled 'cameras on, microphones off' writing blocks to increase accountability and focus, and support self-regulated behaviour (Lee et al., 2021). Staff members provided one-to-one writing and academic skills support.

Even if learners could not be together in person, our students were offered constant ways to connect, question and discuss, and to see others doing the same thing. We saw how virtual community interaction led to self-reported learning benefits immediately:

- Instagram Live events were attended by over 100 students - an improvement on our traditional in-person programming.

- An interactive Rise Articulate module, which included embedded Padlets for discussion, was completed by $94 \%$ of enrolled students. $100 \%$ of students surveyed rated the module as 'very' or 'extremely useful', commenting on how the interactive activities were central to 'increasing my confidence' and 'engaging me'. Students willingly engaged in the discussion tasks by thoughtfully sharing and reacting to ideas - counter to anecdotal suggestions that students would avoid optional tasks.

- Graduate students praised the 'positive invitations and supportive considerations for learning and engagement' of our online group writing space.

\section{Reflections}

Reminding ourselves that even small gains would add up, and offering flexible, constant and responsive forms of community engagement, proved effective. Interventions such as ours might be overshadowed by expensive solutions, but our work offers agility. We can 
make rapid refinements to our programming in response to the pandemic's latest challenge-and, indeed, can do so after its end.

Our approach offers multiple ways to engage in scholarly community for students with accessibility needs and for those who may not feel comfortable participating in discussions or life at a traditional research university. Our increasingly diverse population, who bring unique backgrounds and situations that affect engagement in their studies and scholarly community, were therefore well served by our approach.

We are not experts in tech, and we do not have a big budget for this work. To continue tailoring our approach and keeping up with changes in society, we must keep apprised of students' ever-shifting needs. At SASS, we are instituting a yearly review of new, free technology and interactive options as they reflect student community engagement. As part of the annual review process, we hope to be more mindful of training and development resources consumed in implementing new technologies. By continually planning, we will keep ahead of the curve and avoid panicked sprints in response to future challenges.

No matter what lies ahead, 'return to normal' is not our intention. We are creating a new normal. We encourage others working in the field of learning development to collaborate to find ways to construct (in)formal learning spaces that transcend and connect virtual and physical spaces. Doing so need not be expensive, and our initial data suggest that students may embrace a hybrid online/in-person experience, especially where institutions choose to adopt such learning approaches. Acknowledging that our students wish to belong to and be part of a community is essential to improving both lives and learning experiences.

\section{References}

Bliuc, A.M., Ellis, R.A., Goodyear, P. and Hendres, D.M. (2011) 'Understanding student learning in context: relationships between social identity, perceptions of the learning community, approaches to learning and academic performance', European Journal 
of Psychology of Education, 23(3), pp.417-433. Available at:

https://doi.org/10.1007/s10212-011-0065-6 (Accessed: 6 September 2021).

Hoffman, M., Richmond, J., Morrow, J. and Salomone, K. (2002) 'Investigating "sense of belonging" in first-year college students', Journal of College Student Retention: Research, Theory \& Practice, 4, 227-256. Available at:

https://doi.org/10.2190\%2FDRYC-CXQ9-JQ8V-HT4V (Accessed: 6 September 2021).

Lee, Y., Chung, J.J.Y., Song, J.Y., Chang, M. and Kim, J. (2021) 'Personalizing ambiance and illusionary presence: how people use "Study with me" videos to create effective studying environments', Proceedings of the $2021 \mathrm{CHI}$ Conference on Human Factors in Computing Systems, 355, 1-13. Available at: https://doi.org/10.1145/3411764.3445222 (Accessed: 6 September 2021).

Matthews, K.E., Andrews, V. and Adams, P. (2011) 'Social learning spaces and student engagement', Higher Education Research and Development, 30(2): 105-120. Available at: https://doi.org/10.1080/07294360.2010.512629 (Accessed: 6 September 2021).

Reynolds, K.J., Lee, E., Turner I., Bromhead, D. and Subasic, E. (2017) 'How does school climate impact academic achievement? An examination of social identity processes', Psychological Science, 38(1):135-152. Available at: https://doi.org/10.1177\%2F0143034316682295 (Accessed: 6 September 2021).

Strayhorn, T. (2012) College students' sense of belonging: A key to educational success for all students. London: Routledge.

Suhlmann, M., Sassenberg, K., Nagengast, B. and Trautwein, U. (2018) 'Belonging mediates effects of student-university fit on well-being, motivation, and dropout intention', Social Psychology, 49(1), pp.16-28. Available at: https://psycnet.apa.org/doi/10.1027/1864-9335/a000325 (Accessed: 6 September 2021). 


\section{Author details}

Ian Garner is Manager (Outreach) at Student Academic Success Services (Queen's University). He completed his $\mathrm{PhD}$ at the University of Toronto and has taught languages at school and university level. He has published translations and research in various journals and popular publications, and a book manuscript based on his doctoral work is due for release in 2022.

Lindsay Heggie is an Academic Skills and Writing Specialist at Student Academic Success Services (Queen's University) and holds a PhD in Cognitive Studies of Education from Queen's University. Her publications and research focus on reading development, especially those critical skills children need to become accurate, fluent readers with good comprehension. 